\title{
The Impact of COVID-19 Pandemic on Pharmacy Practices in the Tropics: Nigeria as a Case Study
}

\author{
Nnenna Genevieve Ekechukwu ${ }^{1 *}$, Kenneth Anele $\mathrm{Agu}^{2}$ \\ ${ }^{1}$ Bristol Pharmacy, Gwarimpa, Abuja, Nigeria \\ ${ }^{2}$ Associate Director, Howard University Global Initiative Nigeria, Abuja, Nigeria
}

\begin{abstract}
As the pandemic was sudden and no time was given to prepare for the lockdown measure, pharmaceutical practices were significantly disrupted in the aspects of manufacturing and supplying drugs, sales, and profit-making. Therefore, this study assessed the impacts of COVID-19 crisis on pharmaceutical practices in Nigeria. A descriptive cross-sectional design survey was adopted to draw information from the pharmacists (respondents) among the targeted population. 1,200 professional and practice pharmacists were systematically and randomly selected across the six geopolitical zones in Nigeria, while 1,118 copies of the administered questionnaire were retrieved, coded, and analyzed using descriptive and inferential statistics aided by the Statistical Package for Social Sciences (SPSS) software version 23 to run the analyses. The findings showed that COVID-19 had negative impacts on pharmaceutical practices, especially in hospital and community practices. A 25\%-49\% decrease was highly indicated in sales, purchase orders, and profits, while the majority, 347 (31.04\%) of the respondents, indicated that they had a 1\%-24\% decrease in their workforce. Also, total lockdown as a COVID-19 measure increased the level of insecurity and inflation during the pandemic. $75.13 \%$ of the pharmacists who represent the targeted population indicated that their place of work largely enforced COVID-19 basic preventive measures during the pandemic. This study concludes that necessary efforts should be put in place to ease the affairs of the pharmaceutical practices before, during, and after the pandemic.
\end{abstract}

Keywords: COVID-19, Impact, Lockdown, Pharmaceutical Care, Practices, Nigeria.

\section{Introduction}

The outbreak of the emerging infectious disease, named novel coronavirus (COVID-19), began in December 2019 and spread worldwide [1]. In April 2020, 213 countries, areas, or territories were greatly affected [2]. Globally, COVID-19 spreads to over 220 countries and territories with $172,946,180$ confirmed cases and 3,718,601 deaths, based on the report of June 4, 2021 [3]. Respiratory syndrome coronavirus (MERS-CoV) [4] and Severe Acute Respiratory Syndrome (SARS) are mainly caused by coronaviruses [5]. The pandemic has caused great havoc in the world, which includes but is not limited to human deaths, extraordinary health, and socioeconomic anguish. Similarly, studies have shown that health care workers were at a very high risk of infection during the COVID-19 pandemic [6, 7]. The COVID-19 pandemic affected many sectors, including the pharmaceutical sector and/or practices. All over the world, this pandemic brought unprecedented challenges and changes to all nations, including Nigeria $[8,9,10,11]$. Because of its impacts, basic precautions were recommended for individuals, countries, and regions to stop and/or mitigate the spread of the virus. A commendable method termed lockdown was made as to the directives from governments in different countries (including 
Nigeria) purposely to curb the spread of coronavirus [11].

The lockdown measure is highly restrictive on social freedoms and caused damage to the economy, more importantly in the pharmaceutical industry, care, and/or practices. The concept of 'lockdown' is the restriction of travel, closing of schools and nonessential businesses, banning social gatherings, and asking citizens to shelter in place [12]. Granting these measures have shown to be operational and effective in decreasing social contact, their economic costs are probable to be high.

Nigeria, which chiefly rests on importation to meet its demands, suffered a huge blow to several sectors, including the pharmaceutical industry. Even though the local industry in Nigeria fairs better when compared to its counterparts in other developing countries in Sub-Saharan African [13]. Previous studies showed that Nigeria is only being able to meet $25 \%$ of its local demand. The pharmaceutical market principally relies on the importation of machinery, pharmaceutical ingredients, and quality equipment from abroad [13].

Nigeria that predominantly banks on importation to attain its demands, underwent a massive setback to numerous sectors, including the pharmaceutical industry. Even though the local industry in Nigeria fairs better when compared to its counterparts in other developing countries in Sub-Saharan African [13]. Previous studies showed that Nigeria is only being able to meet $25 \%$ of its local demand. The pharmaceutical market principally relies on the importation of machinery, pharmaceutical ingredients, and quality equipment from abroad [13].

No matter how wealthy a nation or country is regarding the containment and mitigations of the COVID-19 pandemic, it will eventually have a profound influence on the economy in all countries and regions, especially in low- and middle-income nations. Since the COVID-19 outbreak was unexpected and there was no time to get ready for the lockdown style, as well as in the production and distributing of drugs, pharmaceutical practices were significantly disrupted at the local, regional and global levels. COVID-19 also affected pharmaceutical practices in Nigeria, especially in hospital and community pharmacies [14].

Studies have been conducted in different parts of the world on the COVID-19 pandemic related to the impacts and its associated factors $[11,15]$. Many studies had shown the positive impact of pharmaceutical care (PC) in improving patients' clinical, economic, and humanistic outcomes in America, Europe, and Asia [15, 16, 17, 18]. Several studies have been conducted in Africa related to the impact of pharmaceutical care on patients' outcomes, especially [19]. The type of research, such as experimental and non-experimental, recorded the activities and the impact of Pharmaceutical Practices (PC) in disease states [20, 21]. Studies proliferate in Nigeria on the activities of pharmaceutical practice [22, 23]. However, no or few studies have been conducted in assessing the impact of COVID-19 on pharmaceutical practices in Nigeria. Therefore, the impacts of the COVID-19 on pharmaceutical practices in Nigeria were assessed. Specifically, the impact of the pandemic on pharmaceutical care and practices and the strategic measures taken and practiced in the study area were assessed.

\section{Materials and Methods}

The study was confined to the entire Nigeria by selecting few States from each of the six geopolitical zones. Nigeria is located at the extreme inner corner of the Gulf of Guinea on the west coast of Africa and lies between latitudes $4 \mathrm{o}$ and $14 \mathrm{o}$ North of the equator and longitudes 20 42' and $15^{\circ} 00^{\prime}$ 'East of the Greenwich Meridian (Figure 1) [24, 25]. The National Population Commission estimated the population of Nigeria in 2006 at 140,431,790, which placed it among the most populous countries in the world and the most populated country in Africa. The 2016 projected population was 193,392,517 [26], and 2018 
population was put at 197 million [14]. The study area encompasses Abuja and 36 States that are further sectioned into 774 Local Government Areas (LGAs) [27]. The States and FCT are also further grouped into six geopolitical regions: North East, North West, North Central, South East, South West, and South-South regions (Figure 1). The grouping of the zones is based on geographical location, culture, and the historical origin of the regions, to mention but a few [27]. The study area (Nigeria) is classified as low-mid with a growth rate of $2.6 \%$ per year [28].

The method adopted for the study involved a cross-sectional descriptive design which was carried out among the professional and registered pharmacists at different pharmaceutical practices, especially in hospital practice, community practice, and industrial practice in the study area for a specific period. Of the total 21,892 registered pharmacists in the country [29], a total of 1,200 copies of a wellstructured self-made questionnaire were used to collect information from the respondents (registered pharmacists) who served as the sample population. The copies of the questionnaire were administered and/or mailed using a systematic random sampling technique in all the six geopolitical zones of Nigeria. The questionnaire that served as an instrument in this research was tested to ascertain its validity and reliability. The researcher consulted experts and renowned public health researchers by giving them the instrument to review the relevance of the questions on the subject matter to know whether it would test what it was designed for. The data collection tool was also pretested before they were administered. Of the total copies of the questionnaire administered in the study area, 1,118 copies were retrieved, coded in an excel Microsoft Package, and analyzed using SPSS version 23.

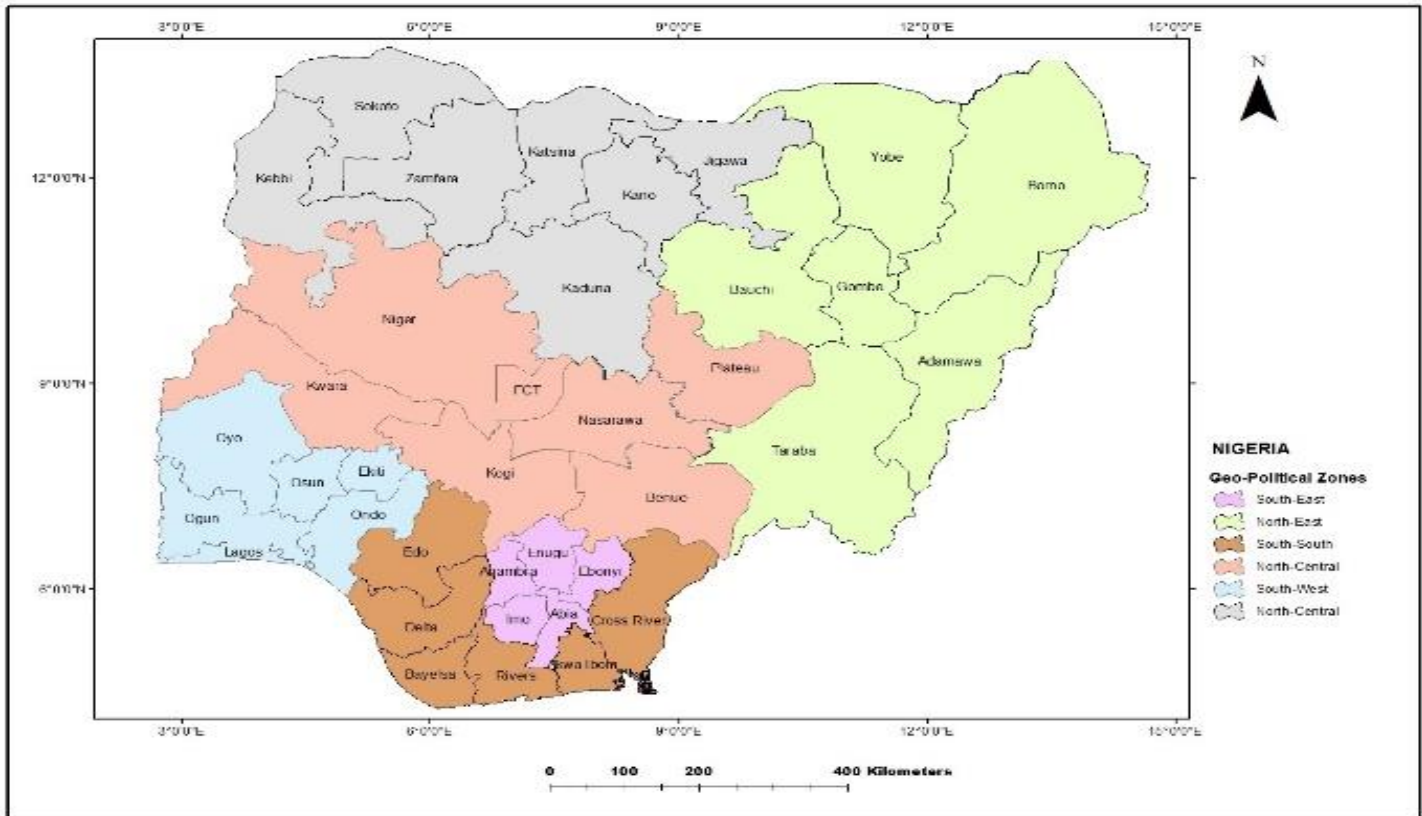

Figure.1. Map of the Study Area, Nigeria

\section{Results}

\section{Demographic Characteristics of the Pharmacists (Respondents)}

Table 1 presents the socio-demographic characteristics of the respondents in the studied area. The result showed that large proportions of the sampled population were male (51.4\%), while only $2.7 \%$ preferred not to indicate their gender. The majority, 939 (84\%) of the targeted population which represents the respondents, were between the ages of 30 and 59. In all the respondents in the study area, $908(81.2 \%)$ were married, $17.9 \%$ were single, and the least 
percentage $(0.9 \%)$ of the respondents constituted those who were separated. In the study area, all the respondents were professional pharmacists with university educational qualifications; $42.5 \%$ with Bachelor of Pharmacy, 25.8\% with Master degree, and 6.3\% with Ph.D. degrees.

Considering the respondents' areas or fields of practice, hospital practice, community practice, and industrial practice constituted larger percentages with $51.2 \%, 1.9 \%$, and $7.2 \%$, respectively (Table 1). Some of the respondents (Pharmacists) also practiced in the areas of health insurance, marketing/production, administrative, political, and NonGovernmental Organizations. A very small number of respondents, which represents $7.1 \%$, have spent 5-9 years in the pharmaceutical practices, while 268 (24.0\%) have spent between 10 and 14 years. Those pharmacists (respondents) who had spent between 20 and 24 years constituted $21.3 \%$, while the respondents who have spent more than 30 years in the practice of pharmacies constituted $8.0 \%$ (Table $1)$.

In terms of the hours spent at work, during the period of COVID-19, the majority, 722 (64.6\%), of the Pharmacists worked for 6-8 hours per day. Regarding the respondents in the selected geopolitical zones, the respondents were equally sampled across of the six zones in the country where South-West, North-Central, and South-East largely participated with larger percentages of $22.3 \%, 21.3 \%$ and 18.5 , respectively.

Table 1. Demographic Characteristics of the Respondents

\begin{tabular}{|l|l|l|l|}
\hline Variables & Frequency & Percent (\%) \\
\hline \multirow{5}{*}{ Gender } & Male & 575 & 51.4 \\
\cline { 2 - 4 } & Female & 513 & 45.9 \\
\cline { 2 - 4 } & Prefer not to say & 30 & 2.7 \\
\cline { 2 - 4 } & Total & $\mathbf{1 1 1 8}$ & $\mathbf{1 0 0 . 0}$ \\
\hline \multirow{5}{*}{ Age Bracket } & $18-29$ & 130 & 11.6 \\
\cline { 2 - 4 } & $30-39$ & 256 & 22.9 \\
\cline { 2 - 4 } & $40-49$ & 357 & 31.9 \\
\cline { 2 - 4 } & $50-59$ & 326 & 29.2 \\
\cline { 2 - 4 } & $60-69$ & 49 & 4.4 \\
\cline { 2 - 4 } & Total & $\mathbf{1 1 1 8}$ & $\mathbf{1 0 0 . 0}$ \\
\hline Earital Status & Single & 200 & 17.9 \\
\cline { 2 - 4 } & Married & 908 & 81.2 \\
\cline { 2 - 4 } & Separated & 10 & 0.9 \\
\cline { 2 - 4 } & Total & $\mathbf{1 1 1 8}$ & $\mathbf{1 0 0 . 0}$ \\
\hline \multirow{5}{*}{ Educational Level } & B. Pharm & 475 & 42.5 \\
\cline { 2 - 4 } & Masters & 288 & 25.8 \\
\cline { 2 - 4 } & Postgraduate Fellowship & 255 & 22.8 \\
\cline { 2 - 4 } & PhD. & 70 & 6.3 \\
\cline { 2 - 4 } & Others & 30 & 2.7 \\
\cline { 2 - 4 } & Total & $\mathbf{1 1 1 8}$ & $\mathbf{1 0 0 . 0}$ \\
\hline \multirow{5}{*}{ Area of Practice } & Academia & 10 & 0.9 \\
\cline { 2 - 4 } & Hospital & 572 & 51.2 \\
\cline { 2 - 4 } & Community & 31.9 \\
\cline { 2 - 4 } & Industrial & & \\
\hline
\end{tabular}




\begin{tabular}{|c|c|c|c|}
\hline & Public Health & 69 & 6.2 \\
\hline & Others & 30 & 2.7 \\
\hline & Total & 1118 & 100.0 \\
\hline \multirow{8}{*}{$\begin{array}{l}\text { Other Areas of } \\
\text { Practice }\end{array}$} & Do not practice in any other area & 1008 & 90.2 \\
\hline & NGO & 10 & 0.9 \\
\hline & Health Insurance & 40 & 3.6 \\
\hline & Marketing/Production & 20 & 1.8 \\
\hline & Academia & 20 & 1.8 \\
\hline & Administrative & 10 & 0.9 \\
\hline & Politics & 10 & 0.9 \\
\hline & Total & 1118 & 100.0 \\
\hline \multirow[t]{8}{*}{ Years of Practice } & $<5$ Years & 179 & 16.0 \\
\hline & $5-9$ Years & 79 & 7.1 \\
\hline & $10-14$ Years & 268 & 24.0 \\
\hline & $15-19$ Years & 108 & 9.7 \\
\hline & $20-24$ Years & 238 & 21.3 \\
\hline & $25-29$ Years & 157 & 14.0 \\
\hline & $\geq 30$ Years & 89 & 8.0 \\
\hline & Total & 1118 & 100.0 \\
\hline \multirow{5}{*}{$\begin{array}{l}\text { Ave. number of daily } \\
\text { hours of work }\end{array}$} & $3-5$ Hours & 20 & 1.8 \\
\hline & $6-8$ Hours & 722 & 64.6 \\
\hline & $9-11$ Hours & 277 & 24.8 \\
\hline & 12 Hours and Above & 99 & 8.9 \\
\hline & Total & 1118 & 100.0 \\
\hline \multirow{7}{*}{$\begin{array}{l}\text { Geo-Political Zone of } \\
\text { Practice }\end{array}$} & South-West & 249 & 22.3 \\
\hline & South-South & 169 & 15.1 \\
\hline & South-East & 207 & 18.5 \\
\hline & North-Central & 238 & 21.3 \\
\hline & North-East & 117 & 10.5 \\
\hline & North-West & 138 & 12.3 \\
\hline & Total & 1118 & 100.0 \\
\hline
\end{tabular}

\section{Impact of COVID-19 on Pharmaceutical Practices}

The impacts of the COVID-19 pandemic on all aspects of pharmaceutical work and/or enterprise are presented in Figure 2. The results showed that larger percentages of the pharmacists experienced a decline in their work/enterprise. $25 \%-49 \%$ decrease was highly indicated in sales, purchase orders, and profits. The majority, 347 (31.04\%), indicated that they had a $1 \%-24 \%$ decrease in their workforce, while 337 (30.14\%) of the pharmacists (respondents) indicated that COVID-19 had no impact on production. Also, the majority 374 $(33.45 \%)$ and 326 (29.16) of the sampled population revealed that COVID-19 affected sales, accounting for a $25 \%-49 \%$ decrease and $1 \%-24 \%$ decrease, respectively.

Table 2 presents the results of how COIVID19 impacted on work/enterprise of different areas of pharmaceutical practices. Hospital and community practices were greatly affected in sales with $51.16 \%$ and $31.93 \%$, respectively. The sales had a percentage decrease of $1 \%-24 \%$ and $25 \%-49 \%$, while the purchasing orders of the work/enterprise had a decrease of 1\%-24\% and $25 \%-49 \%$, which accounted for 37.84 and 
$31.34 \%$, respectively, as shown by the respondents. However, the impacts were greatly felt on Hospital practice and community practice with $51.16 \%$ and $31.93 \%$. In addition, $23.79 \%$, which represents 266 respondents, had shown that they experienced a $25-49 \%$ drop in the profit of the hospital pharmaceutical practice and $9.66 \%$ of the community practice because of the COVID-19 pandemic. Only 10 $(0.89 \%)$ respondents showed that COVID-19 had a 50-100\% profit increase in both hospital and community practices. Because of the impacts of the COVID-19 crisis and/or pandemic in the study area, $369(33.01 \%)$ of the pharmacists temporarily stopped working (Figure 3). This has profound effects on customers and the populace to provide treatment for illnesses and other infectious diseases. Among the $33.01 \%$ of the respondents who had temporarily stopped working because of the impact of the COVID-19, larger percentages of the respondents were in the hospital pharmacies, community pharmacies, and industrial, pharmaceutical practice with $20.48 \%, 7.16 \%$, and $3.58 \%$, respectively (Figure 4).

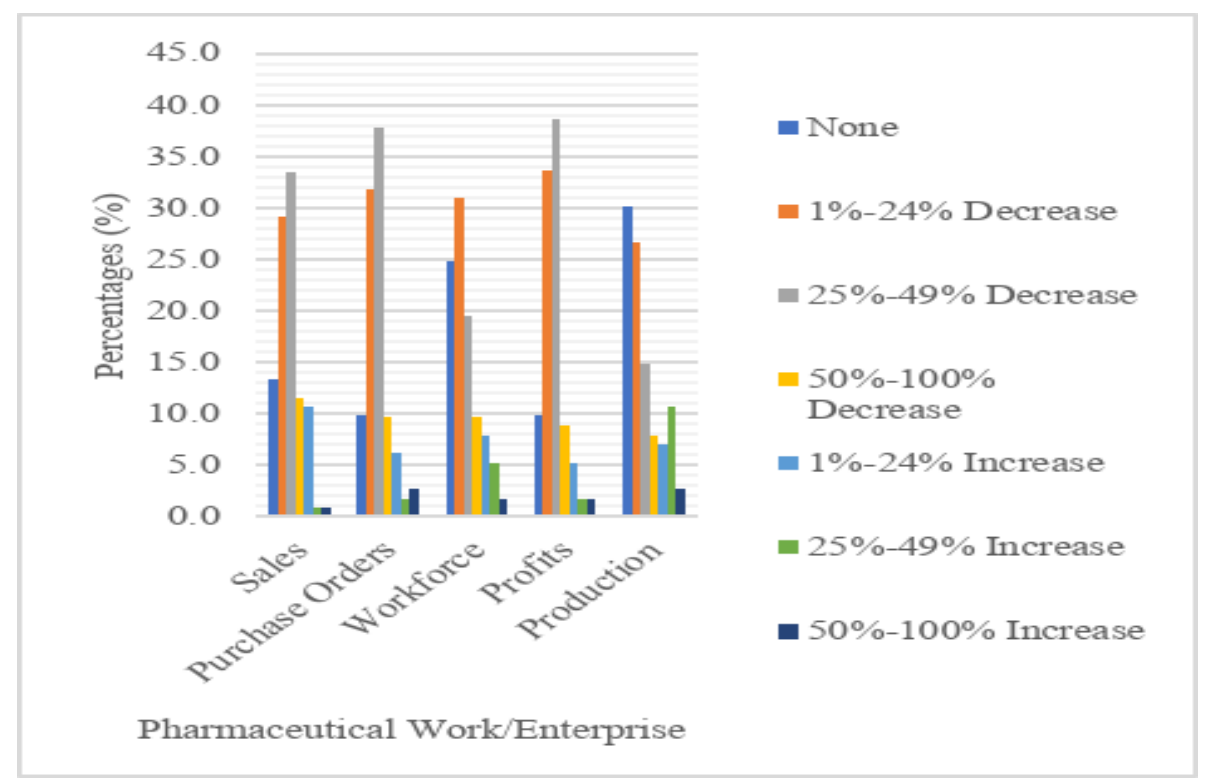

Figure. 2. Impact of COVID-19 Pandemic on Pharmaceutical Practices in the Study Area

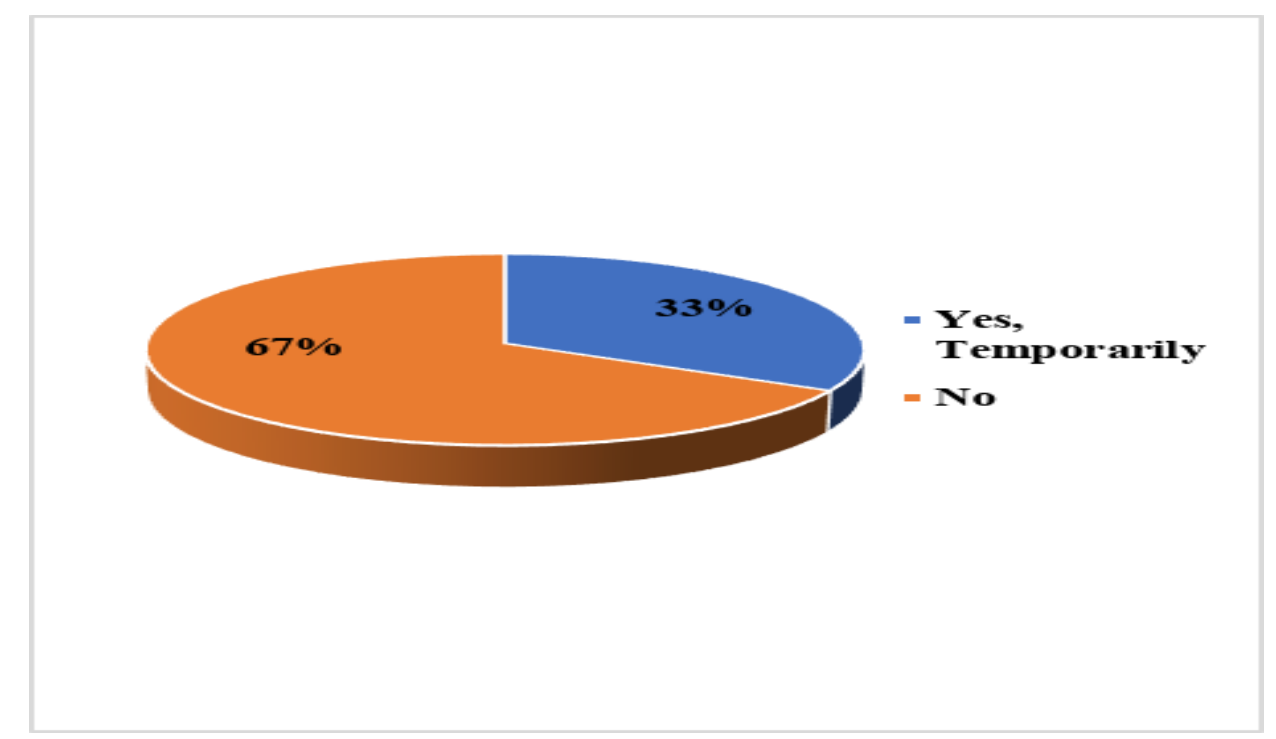

Figure 3. Rate at which Workers stopped Working because of COVID-19 Crisis 
Table 2. Cross Tabulation of the Impacts of COVID-19 and Pharmaceutical Practices

\begin{tabular}{|c|c|c|c|c|c|c|c|c|}
\hline \multirow[t]{2}{*}{ Work/Enterprise } & \multirow[t]{2}{*}{ Percentages of the Impact } & \multicolumn{6}{|c|}{ Area of Practice } & \multirow[t]{2}{*}{ Total } \\
\hline & & Academia & Hospital & Community & Industrial & Public Health & Others & \\
\hline \multirow[t]{8}{*}{ Sales } & None & $10(0.89)$ & $70(6.26)$ & $40(3.58)$ & $10(0.89)$ & $10(0.89)$ & $10(0.89)$ & $150(13.42)$ \\
\hline & $1 \%-24 \%$ Decrease & 0.0 & $178(15.92)$ & $99(8.86)$ & $20(1.79)$ & $9(0.81)$ & $20(1.79)$ & $326(29.16)$ \\
\hline & $25 \%-49 \%$ Decrease & 0.0 & $206(18.43)$ & $118(10.55)$ & 0.0 & $50(4.47)$ & 0.0 & $374(33.45)$ \\
\hline & $50 \%-100 \%$ Decrease & 0.0 & $89(7.96)$ & 0.0 & $40(3.58)$ & 0.0 & 0.0 & $129(11.54)$ \\
\hline & $1 \%-24 \%$ Increase & 0.0 & $29(2.59)$ & $80(7.16)$ & $10(0.89)$ & 0.0 & 0.0 & $119(10.64)$ \\
\hline & $25 \%-49 \%$ Increase & 0.0 & 0.0 & $10(0.89)$ & 0.0 & 0.0 & 0.0 & $10(0.89)$ \\
\hline & $50 \%-100 \%$ Increase & 0.0 & 0.0 & $10(0.89)$ & 0.0 & 0.0 & 0.0 & $10(0.89)$ \\
\hline & Total & $10(0.89)$ & $572(51.16)$ & 357(31.93) & $80(7.16)$ & $69(6.17)$ & $30(2.68)$ & $1118(100)$ \\
\hline \multirow[t]{8}{*}{ Purchase Orders } & None & $10(0.89)$ & $30(2.68)$ & $30(2.68)$ & $10(0.89)$ & $10(0.89)$ & $20(1.79)$ & $110(9.84)$ \\
\hline & $1 \%-24 \%$ Decrease & 0.0 & $178(15.92)$ & $109(9.75)$ & $20(1.79)$ & $39(3.49)$ & $10(0.89)$ & $356(31.84)$ \\
\hline & $25 \%-49 \%$ Decrease & 0.0 & $275(24.60)$ & $128(11.45)$ & 0.0 & $20(1.79)$ & 0.0 & $423(37.84)$ \\
\hline & $50 \%-100 \%$ Decrease & 0.0 & $59(5.28)$ & $10(0.89)$ & $40(3.58)$ & 0.0 & 0.0 & $109(9.75)$ \\
\hline & $1 \%-24 \%$ Increase & 0.0 & 0.0 & $60(5.37)$ & $10(0.89)$ & 0.0 & 0.0 & $70(6.26)$ \\
\hline & $25 \%-49 \%$ Increase & 0.0 & $10(0.89)$ & $10(0.89)$ & 0.0 & 0.0 & 0.0 & $20(1.79)$ \\
\hline & $50 \%-100 \%$ Increase & 0.0 & $20(1.79)$ & $10(0.89)$ & 0.0 & 0.0 & 0.0 & $30(2.68)$ \\
\hline & Total & $10(0.89)$ & $572(51.16)$ & 357(31.93) & $80(7.16)$ & $69(6.17)$ & $30(2.68)$ & 1118(100) \\
\hline \multirow[t]{8}{*}{ Workforce } & None & $10(0.89)$ & $109(9.75)$ & $60(5.37)$ & $60(5.37)$ & $29(2.59)$ & $10(0.89)$ & $278(24.87)$ \\
\hline & $1 \%-24 \%$ Decrease & 0.0 & $159(14.22)$ & $158(14.13)$ & $10(0.89)$ & 0.0 & $20(1.79)$ & $347(31.04)$ \\
\hline & $25 \%-49 \%$ Decrease & 0.0 & $159(14.22)$ & $39(3.49)$ & 0.0 & $20(1.79)$ & 0.0 & $218(19.50)$ \\
\hline & $50 \%-100 \%$ Decrease & 0.0 & $68(6.08)$ & $30(2.68)$ & $10(0.89)$ & 0.0 & 0.0 & $108(9.66)$ \\
\hline & $1 \%-24 \%$ Increase & 0.0 & $38(3.40)$ & $50(4.47)$ & 0.0 & 0.0 & 0.0 & $88(7.87)$ \\
\hline & $25 \%-49 \%$ Increase & 0.0 & $39(3.49)$ & $20(1.79)$ & 0.0 & 0.0 & 0.0 & $59(5.28)$ \\
\hline & $50 \%-100 \%$ Increase & 0.0 & 0.0 & 0.0 & 0.0 & $20(1.79)$ & 0.0 & $20(1.79)$ \\
\hline & Total & $10(0.89)$ & $572(51.16)$ & $357(31.93)$ & $80(7.16)$ & $69(6.17)$ & $30(2.68)$ & 1118(100) \\
\hline Profits & None & $10(0.89)$ & $30(2.68)$ & $30(2.68)$ & $10(0.89)$ & $10(0.89)$ & $20(1.79)$ & $110(9.84)$ \\
\hline
\end{tabular}




\begin{tabular}{|c|c|c|c|c|c|c|c|c|}
\hline & $1 \%-24 \%$ Decrease & 0.0 & $168(15.03)$ & $139(12.43)$ & $50(4.47)$ & $20(1.79)$ & 0.0 & $377(33.72)$ \\
\hline & $25 \%-49 \%$ Decrease & 0.0 & $266(23.79)$ & $108(9.66)$ & $10(0.89)$ & $39(3.49)$ & $10(0.89)$ & $433(38.73)$ \\
\hline & 50\%-100\% Decrease & 0.0 & $79(7.07)$ & $10(0.89)$ & $10(0.89)$ & 0.0 & 0.0 & $99(8.86)$ \\
\hline & $1 \%-24 \%$ Increase & 0.0 & $19(1.70)$ & $40(3.58)$ & 0.0 & 0.0 & 0.0 & $59(5.28)$ \\
\hline & $50 \%-100 \%$ Increase & 0.0 & $10(0.89)$ & $10(0.89)$ & 0.0 & 0.0 & 0.0 & $20(1.79)$ \\
\hline & Total & $10(0.89)$ & 572(51.16) & 357(31.93) & $80(7.16)$ & $69(6.17)$ & $30(2.68)$ & 1118(100) \\
\hline \multirow[t]{7}{*}{ Production } & None & $10(0.89)$ & $208(18.60)$ & $50(4.47)$ & $20(1.79)$ & $19(1.70)$ & $30(2.68)$ & $337(30.14)$ \\
\hline & $25 \%-49 \%$ Decrease & 0.0 & $68(6.08)$ & $78(6.98)$ & 0.0 & $20(1.79)$ & 0.0 & $166(14.85)$ \\
\hline & $50 \%-100 \%$ Decrease & 0.0 & $69(6.17)$ & $20(1.79)$ & 0.0 & 0.0 & 0.0 & $89(7.96)$ \\
\hline & $1 \%-24 \%$ Increase & 0.0 & $29(2.59)$ & $40(3.58)$ & $10(0.89)$ & 0.0 & 0.0 & $79(7.07)$ \\
\hline & $25 \%-49 \%$ Increase & 0.0 & $70(6.26)$ & $39(3.49)$ & 0.0 & $10(0.89)$ & 0.0 & $119(10.64)$ \\
\hline & $50 \%-100 \%$ Increase & 0.0 & $10(0.89)$ & $10(0.89)$ & 0.0 & $10(0.89)$ & 0.0 & $30(2.68)$ \\
\hline & Total & $10(0.89)$ & 572(51.16) & 357(31.93) & $80(7.16)$ & $69(6.17)$ & $30(2.68)$ & 1118(100.0) \\
\hline
\end{tabular}




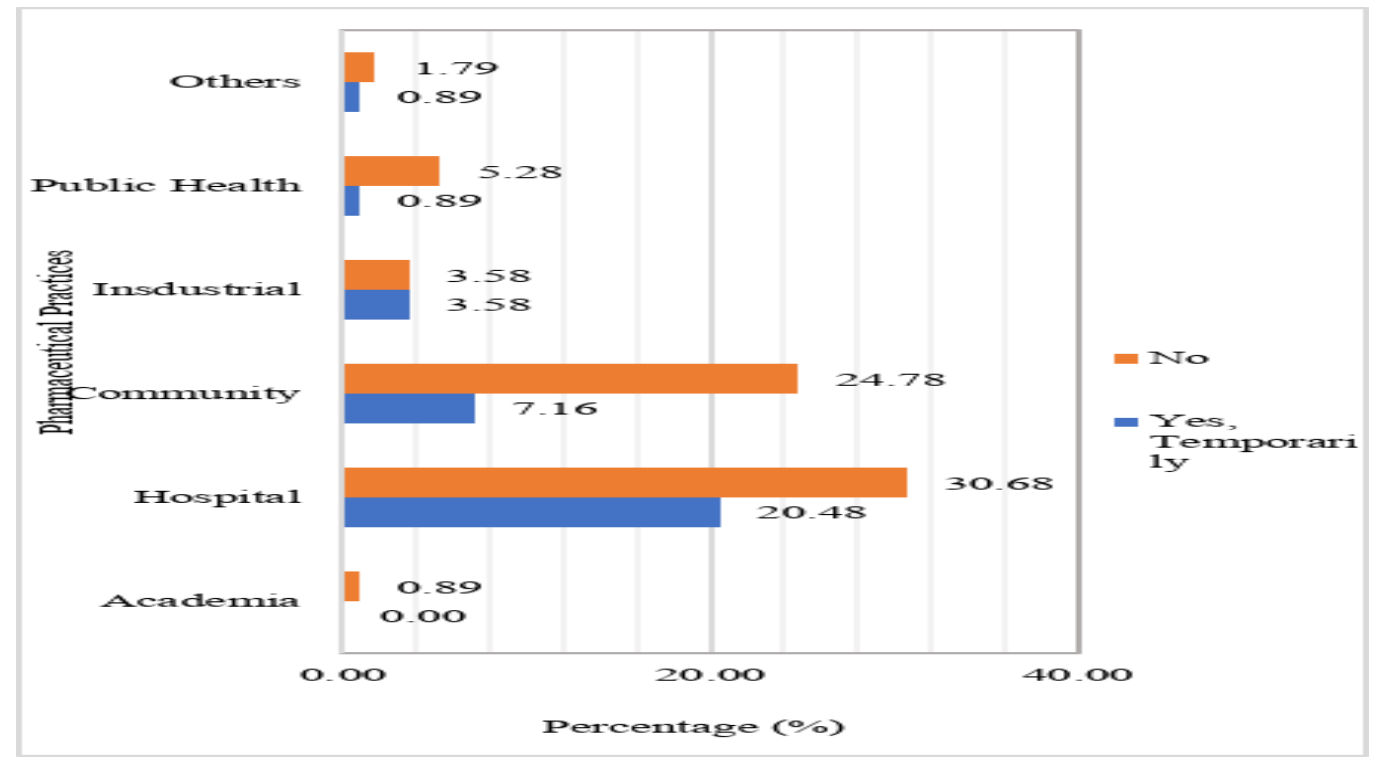

Figure 4. Rate at which Workers Stopped Working in the Pharmaceutical Practices because of COVID-19

Crisis

Figure 5 shows the extent to which the COVID-19 pandemic affected pharmaceutical work and/or business in Nigeria. The results of the study revealed that the pharmaceutical work and/or business was greatly affected by the COVID-19 pandemic, as indicated by the majority $506(45.26 \%)$ of the pharmacists (respondents), while 404 (36.14\%) indicated that their business was somewhat affected. This justifies that $81.40 \%$ of them indicated that the COVID-19 crisis affected their work and business.

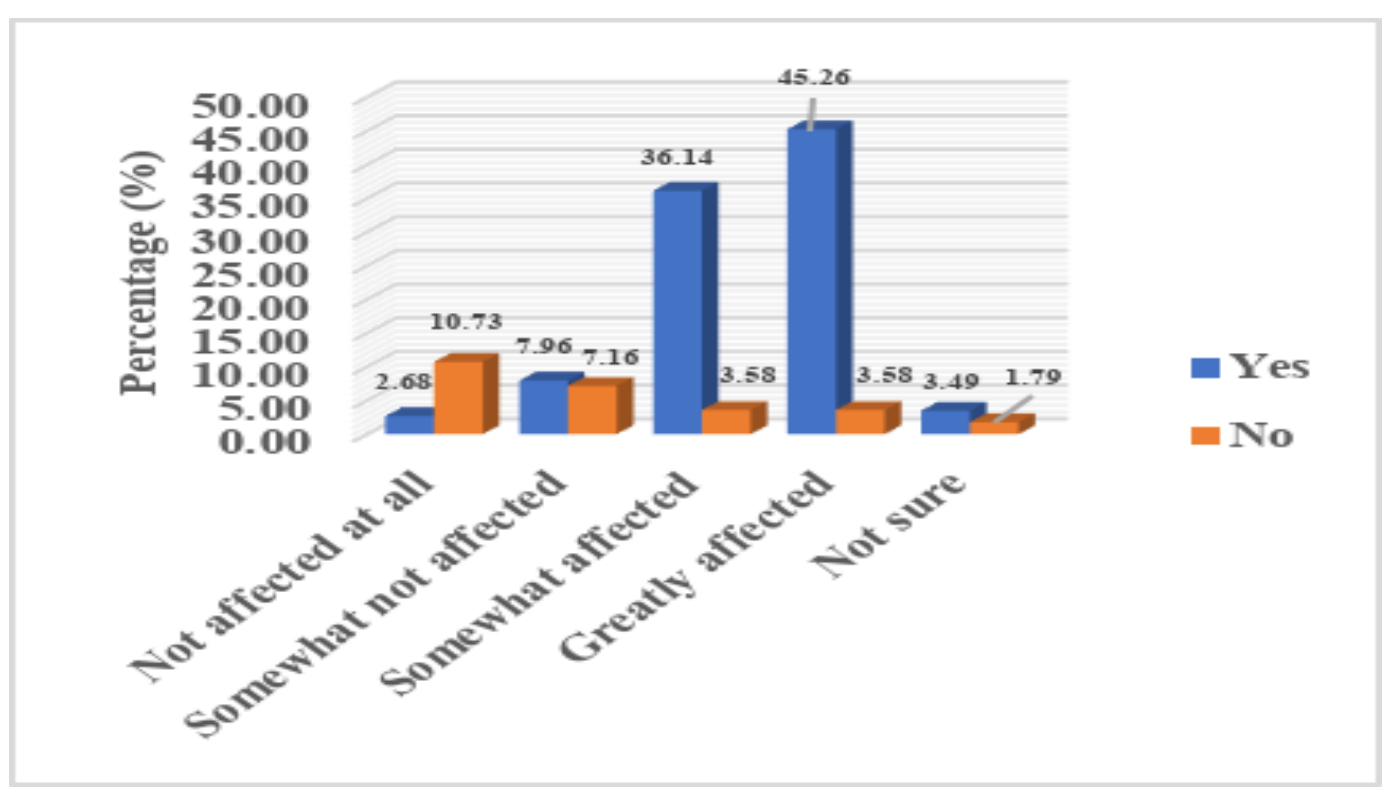

Figure 5. The Extent at which COVID-19 Pandemic affected Pharmaceutical Work and/or Business 
Strategic Measures Taken and Practiced as Responses to COVID-19 Crisis by Respondents in the Study Area

The outcomes of this study found out that the lockdown method, as a universal strategic measure of reducing the spread and extent of COVID-19, was associated with the level of spreading COVDI-19 and insecurity and inflation (Figure. 6). 49.82\% of the respondents (Pharmacists) agreed that total lockdown measure taken and practiced during COVID-19 reduced the spread of 2019 coronavirus disease (COVID-19) in the study area, while $40.70 \%$ of the respondents also agreed that total lockdown increased the level of insecurity and inflation in the course of the COVID-19 pandemic.

Table 3 shows that Pharmacists have taken and practiced some measures to mitigate and/or control the impacts of COVID-19 on the pharmaceutical practices in the study area.

'Diversifying sales channels through online marketing and free delivery (19.41\%)' was highly indicated by the pharmacists in the study area, followed by 'increased production due to increased demand (17.71\%)' and 'negotiating pays with staff $(16.82 \%)$. Hospital pharmacy and community pharmacy greatly responded to the impact caused by the COVID-19 pandemic with percentages of $51.16 \%$ and $31.93 \%$, respectively. Academia pharmaceutical practice was not involved in mitigating the impact of the COVID-19 pandemic in Nigeria as most of the schools and institutions were closed down during the pandemic.

Industrial, pharmaceutical practice responded to the COVID-19 pandemic by 'reducing the production of goods and services $(3.58 \%)$ '. Besides the available measures recommended and practiced by the organization/enterprise (Table 3), a small proportion of 158 (14.13\%) of the respondents indicated that they put some other strategic measures in place in response to the COVID-19 pandemic. Some other measures practiced by the pharmacists in the study area include working from home; teaching and carrying out examination online; use of virtual work tools, reducing the purchase of commodities due to paucity of funds; ensuring the use of face masks always; and providing the needed materials and equipment to end the virus.

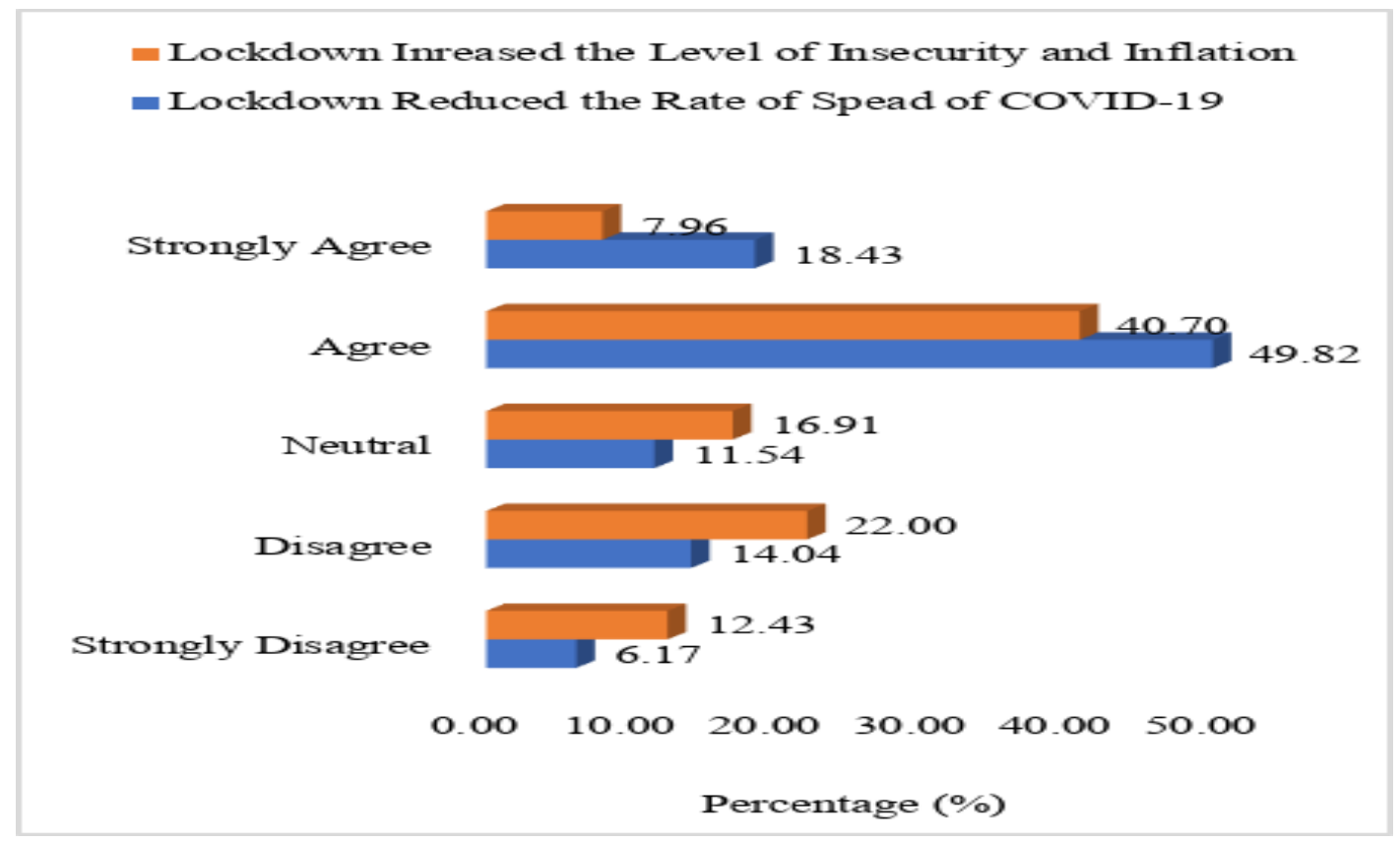

Figure. 6: Lockdown Measure with the Spread of COVID-19 and Level of Insecurity in the Study Area 
Table 3. How Pharmaceutical Organization/Enterprise responded to COVID-19

\begin{tabular}{|l|l|l|l|l|l|l|l|}
\hline \multirow{2}{*}{$\begin{array}{l}\text { How is your } \\
\text { organization/enterprise } \\
\text { responding to the pandemic? }\end{array}$} & Area of Practice & \multicolumn{3}{l|}{ Total } \\
\cline { 2 - 8 } & Academia & Hospital & Community & Industrial & $\begin{array}{l}\text { Public } \\
\text { Health }\end{array}$ & Others & \\
\hline $\begin{array}{l}\text { Regotiating pays with staff } \\
\text { staff }\end{array}$ & 0.0 & $78(6.98)$ & $80(7.16)$ & $20(1.79)$ & $10(0.89)$ & 0.0 & $188(16.82)$ \\
\hline $\begin{array}{l}\text { Reducing the numbers of } \\
\text { staff }\end{array}$ & 0.0 & $110(9.84)$ & $19(1.70)$ & 0.0 & $30(2.68)$ & 0.0 & $159(14.22)$ \\
\hline $\begin{array}{l}\text { Diversifying sales channels } \\
\text { through online marketing } \\
\text { and free delivery }\end{array}$ & 0.0 & $78(6.98)$ & $129(11.54)$ & $10(0.89)$ & 0.0 & 0.0 & $217(19.41)$ \\
\hline $\begin{array}{l}\text { Negotiating payment terms } \\
\text { with banks and suppliers }\end{array}$ & 0.0 & $30(2.68)$ & $69(6.17)$ & $10(0.89)$ & 0.0 & 0.0 & $109(9.75)$ \\
\hline $\begin{array}{l}\text { Reducing the production of } \\
\text { goods and services }\end{array}$ & 0.0 & $19(1.70)$ & $10(0.89)$ & $40(3.58)$ & 0.0 & 0.0 & $69(6.17)$ \\
\hline $\begin{array}{l}\text { Increased production due to } \\
\text { increased demand }\end{array}$ & 0.0 & $168(15.03)$ & $20(1.79)$ & 0.0 & 0.0 & $10(0.89)$ & $198(17.71)$ \\
\hline Others & $10(0.89)$ & $79(7.07)$ & $20(1.79)$ & 0.0 & $29(2.59)$ & $20(1.79)$ & $158(14.13)$ \\
\hline Total & $10(0.89)$ & $572(51.16)$ & $357(31.93)$ & $80(7.16)$ & $69(6.17)$ & $30(2.68)$ & $1118(100)$ \\
\hline
\end{tabular}

Considering the enforcement of COVID-19 basic preventive measures and practices recommended by the World Health Organisation (WHO) and Nigerian Centre for $(75.13 \%)$ of the respondents indicated that their place of work enforced COVID-19 basic preventive measures and to a great extent during the period of the pandemic (Figure 7).

Disease and Control (NCDC), the majority

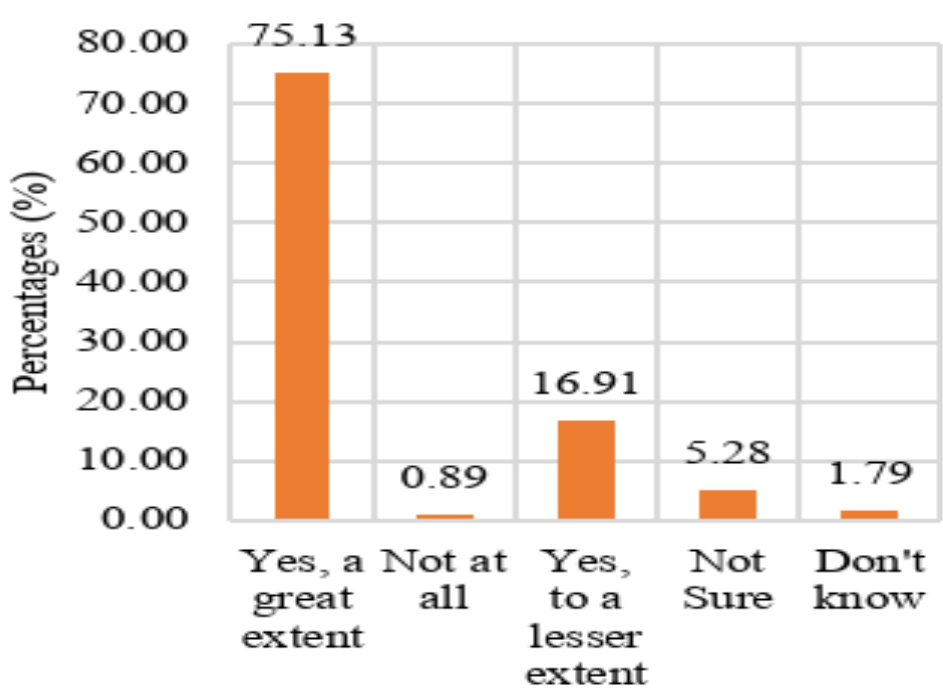

- Percent

Basic Measures and Practices

Figure 7. Enforcement of COVID-19 Basic Preventive Measures and Practices

Larger proportions of the respondents which constituted $209(18.69 \%)$ and $199(17.80 \%)$, had shown that their places of work enforced COVID-19 basic preventive measures and 
practices in North-central and South-west of enforced COVID-19 basic preventive measures Nigeria (Figure 8 ). Only $1.70 \%$ of the targeted in the northwest of the country. respondents were not sure if their place of work

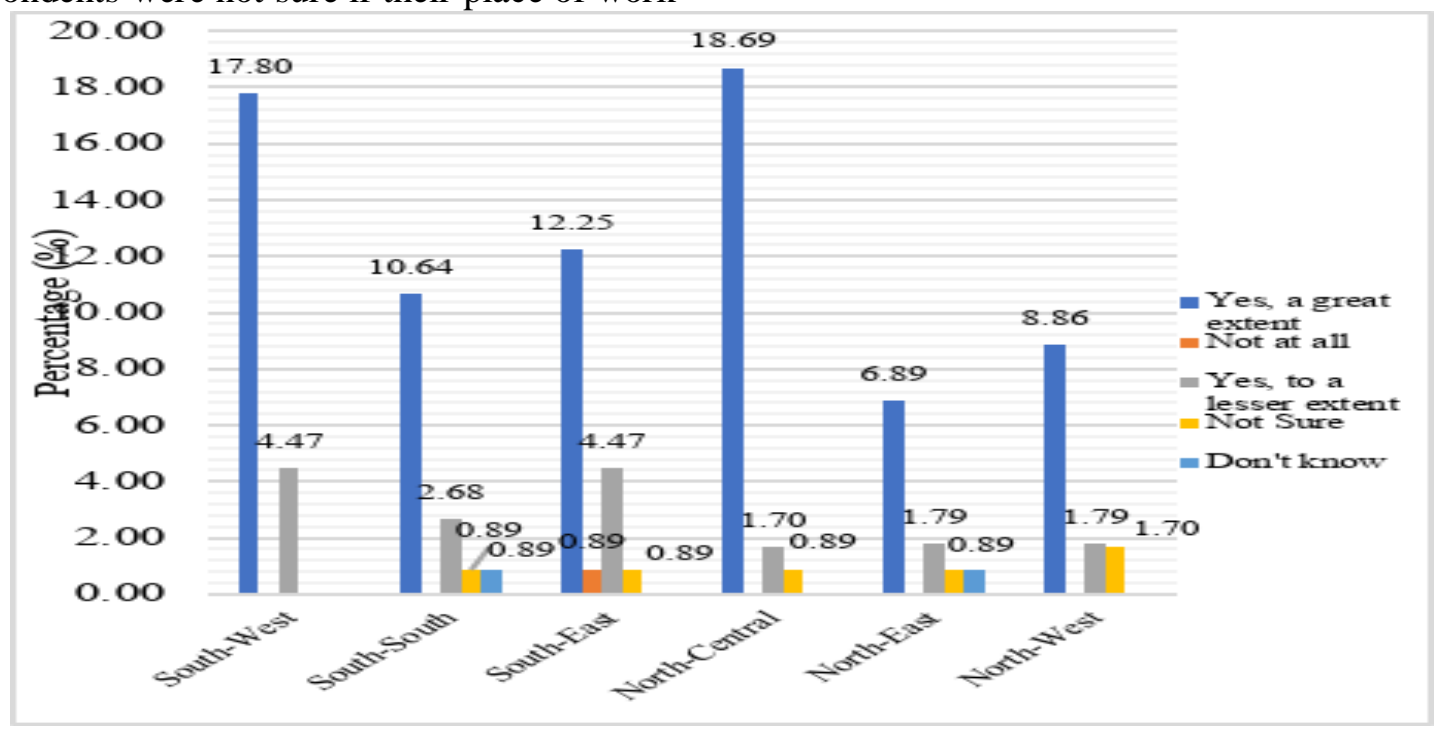

Figure. 8. Enforcement of COVID-19 Basic Preventive Measures and Practices in Geo-Political Zones

Among the working places that enforced COVID-19 basic preventive measures and practices, a large proportion 860 (76.92\%) of the respondents practiced 'social and physical distancing at work,' $75.31 \%$ of respondents practiced the 'use of PPEs and temperature checks', while only 40 (3.58\%) practiced other basic procedures which include the use of only face mask, face mask, and shield, face mask and gloves, regular handwashing with water and soap and, and the use of hand sanitizers (Figure 9).

\section{Discussion}

Pharmacists and pharmaceutical practices play significant roles in upholding and improving the health status of Nigerians. Because of the sudden emergence of COVID19 and no time to prepare for the lockdown measure concerning the manufacturing and supplying of drugs, pharmaceutical practices were significantly disrupted. Findings obtained in this study revealed the percentages of males and females varied as the ratio of males and females were 0.51 and 0.46. A decline in the percentage of aged people sampled in the study area could be a result of the population pyramid in Nigeria, which tends to be a less aged group at the apex. Because of the nature of the profession and/or work, all the respondents were professional pharmacists with a minimum of university educational qualifications, while some respondents also had other professional qualifications. Large proportions of the community, hospital and industrial practices justified the fact that the three pharmaceutical practices were immensely contributed to their quota during the COVID-19 pandemic. This is similar to the report of the previous studies such as [30].

Findings from this study also revealed that pharmaceutical practices were negatively affected in areas or aspects of sales, purchase orders, and profit-making, especially in hospital and community pharmaceutical practices in Nigeria, the study area. Based on the results of this study, the decrease in all areas/aspects of the pharmaceutical practices could be ascribed to the lockdown approach, and other factors such as low supplying of drugs, low production or manufacturing of drugs, low income, to mention but a few. The decrease in the workforce could be attributed to the fear of getting contracted with the virus in the study area. It is believed that the team of pharmacy teams are considered as important members of 
the healthcare workforce and also as the crucial frontline of healthcare workers [30]. Because they (pharmacy workforce) provide and/or offers an extensive array of healthcare services in pharmaceutical practices, especially community pharmacies [31].

The reason for the $25-49 \%$ decrease in the profit of the hospital and community pharmaceutical practices was due to the fact of low patronage and the fear of COVID-19 among the populace. Furthermore, several factors caused a temporary stoppage of working in the hospital, community, and industrial practices during COVID-19 by the respondents. The findings of this study corroborate the findings of [14]. Short-term impacts of the COVID-19 pandemic involve demand changes, regulation and revision, development process and research, and the shift towards telecommunications and telemedicine [32]. Many studies showed the adverse psychological health effects following quarantine which include emotional disturbance, depression, stress, low mood, irritability, insomnia, posttraumatic stress symptoms, anger, and emotional exhaustion [33 - 36]. Additionally, it has been stated that confusion, anger, and posttraumatic stress indicators caused by being quarantined for a long period, the panic of getting the virus, distress, boredom, insufficient supplies, poor information, monetary loss, and stigma are adverse psychological effects following quarantine [37].

The adoption of mitigation strategies of COVID-19 was practiced by a large number of respondents. This might be the result of the awareness and education level of the pharmacists (respondents). The consequent effect of lockdown brought about a high level of insecurity and inflation. An upsurge in the level of insecurity could be a result of difficulties people faced to feed themselves and other things during the lockdown period. Low supplies caused a persistent rise in the prices of goods and services during COVID-19. Previous studies have identified the psycho-social impact caused by lockdown measures [38]. The evidence has been reported the sufferings of psychological distress, insomnia, anxiety, and depression among the healthcare providers [39, 40].

The actions taken by the pharmacists during COVID-19 were because of the impact of COVID-19 on several aspects/areas of pharmaceutical practices in Nigeria, the study area. Studies reported many factors are associated with the impact of COVID-19. Also, the occurrence of anxiety was $60 \%$, and depression was $53 \%$, mostly mild and moderate levels, for the time being, just one out of four respondents testified the accessibility of mental health support team at the workplace among 2097 healthcare workers from 31 countries [15]. Due to the impact of the COVID-19 pandemic, actions were mostly taken by the hospital and community pharmaceutical practices. In the earlier studies, it has been established that respondents (pharmacists) are in a crucial position to provide an effective response to the COVID-19 pandemic, yet their expertise is not often recognized and underutilized [41]. In countries like Northern Ireland and New Zealand, the government acknowledged pharmacists' contributions by providing extra remuneration during the pandemic [42].

Findings obtained from this study further showed that the respondents' working place enforced and practiced basic preventive measures meant for COVID-19. It has been reported and recommended in the previous studies that healthcare systems should address the psychological burden among healthcare workers during the COVID-19 pandemic [15]. In spite of the fact that the government took actions towards the impacts of COVID-19, individuals also took proactive measures to curb the symptoms of COVID-19 [43]. In a similar study conducted in India, it was reported that there was a frequent visitation to hospitals for the actions to be taken regarding 
the emergence of COVID-19 by individuals [44].

The major basic COVID-19 preventive measures practiced by the pharmacists which constituted the respondents included 'social and physical distancing at work', 'use of PPEs and temperature checks', 'the use of only face mask, face mask and shield, face mask and gloves, frequent handwashing with water and soap, and the hand sanitizers'. The findings of this study correspond to the study of which reported social distancing, and the use of face masks was the most often reported by the pharmacists for prevention [45]. An online and/or conducted in Nigeria showed that wearing face masks, covering of mouth while sneezing, and avoiding crowded places are selfreported as practices among respondents [46].

Furthermore, the chance of positive mitigation strategies and/or practices towards COVID-19 was associated with a positive perception of the risk involved [47]. In Nigeria, previous studies also substantiate the pivotal role of positive risk perception on imbibing COVID-19 mitigating strategies and/or protective measures and attitudes [48]. The results obtained in this study are similar to the Knowledge concerning the practice of face masks in Saudi Arabia [49]. Because of the deadly nature of COVID-19, it has presented anxiety and/or fear in every individual with similar symptoms of illness [47]. Previous studies had shown that fear could prompt

\section{References}

[1] Lai, J., Ma, S., Wang, Y., Cai, Z., Hu, J., Wei, N., et al. 2020, Factors associated with mental health outcomes among health care workers exposed to coronavirus disease 2019. JAMA Netw Open, 3:e203976.

Doi:10.1001/ jamanetworkopen.2020.3976.

[2] World Health Organization, 2020, Coronavirus disease (COVID-19) Pandemic 2020. Available: https://www.who.int/emergencies/diseases/novelcoronavirus-2019. Accessed: 8 September 2021. healthy behavior among people or individuals, most importantly the period of a pandemic, but such behavior cannot be viable [50, 51, 52].

\section{Conclusion and Recommendation}

Pharmacists play significant roles to uphold and improving the health status of Nigerians. In this respect, the impact of COVID-19 on pharmaceutical practices has been assessed because of its unprecedented impacts on the pharmaceutical practices and the lives of healthcare professionals in the country. This study showed that COVID-19 had negative impacts on pharmaceutical practices, especially in hospital practices and community practices in the study area. Basic precautionary measures and actions towards the impact of COVID-19 in the study area were also enforced and practiced. Supports and assistance from government and non-governmental organizations are needed to better improve pharmaceutical care and services in Nigeria.

\section{Conflicts of Interest}

There is no conflict of interest between the authors.

\section{Acknowledgements}

The author expresses her appreciation and gratitude to all pharmacists and/or pharmaceutical practices and Afeez Alabi Salami for their willingness, assistance, and cooperation to participate in this study.

[3] World Health Organisation, 2021, COVID-19 report cases.

http://www.who.int/gho/countries/nga.pdf?ua=1.

[4] WHO, 2020, Middle East respiratory syndrome coronavirus (MERS-CoV). Available: https://www.who.int/emergencies/mers-cov/en/ Accessed: 8 September 2021.

[5] WHO, 2020, Severe Acute Respiratory Syndrome (SARS). Available: https://www.who.int/csr/sars/en/ Accessed: 7 September 2021. 
[6] The Lancet, 2020, COVID-19: protecting healthcare workers. $\quad$ Lancet. doi:10.1016/S01406736(20)30644-9.

[7] Fatjona et aL. 2021, Impact of COVID-19 pandemic on mental health, risk perception and coping strategies among health care workers in Albania - evidence that needs attention. Clinical Epidemiology and Global Health, 12(2021)100824, 1-7. https://doi.org/10.1016/j.cegh.2021.100824.

[8] Lucero-Prisno, D.E., Adebisi, Y.A., and Lin, X., 2020, Current efforts and challenges facing responses to 2019-nCoV in Africa. Glob Health Res Policy, 5, 21. https://doi.org/10.1186/s41256-02000148-1.

[9] WHO, 2020, Mental health and psychosocial considerations during the COVID-19 outbreak. https://www.who.int/docs/default-

source/coronaviruse/mental-health-

considerations.pdf?sfvrsn=6d3578af_2;2020.

[10]Zhu, N., Zhang, D., Wang, W., et al., 2020, A novel coronavirus from patients with pneumonia in China, 2019. N Engl J Med. 382(8), 727-733. https://doi.org/10.1056/NEJMoa2001017.

[11]Roy, R.M. et al. 2021, Psychological distress during pandemic Covid-19 among adult general population: Result across 13 countries. Clinical Epidemiology and Global Health, 10 (2021), 100708, 1-6.

https://doi.org/10.1016/j.cegh.2021.100708.

[12] Scherbina, B., 2020, Determining the optimal duration of the COVID-19 suppression policy: A cost-benefit analysis. AEI Economics Working Paper 2020-03. American Enterprise Institute, 1-28.

[13] Akande-Sholabi, W., Adebisi, Y.A., Bello, A., and Ilesanmi, O.S., 2020, COVID-19 in Nigeria: Is the pharmaceutical sector spared? Public Health in Practice, 1 1, 100044. https://doi.org/10.1016/j.puhip.2020.100044.

[14] David, K.B., and Adebisi, Y.A., 2020, Proposed model for hospital and community pharmacy services during COVID-19 pandemic in Nigeria. Int J Pharm Pract, 28, 544-545.

[15] Mila, N.N.H., Roy, R.M., Ayesha, A., Fatjona, K., Radwa, A.E., Jeldah, M.N., and Adinegara, L.A., 2020, Immediate impact of COVID-19 on mental health and its associated factors among healthcare workers: A global perspective across 31 countries. Viewpoints, 10(2), 020381, 1-6. doi: 10.7189/jogh.10.020381.

[16] Wagner, E.H., 1998, Chronic disease management: What will it take to improve care for chronic illness? Efficient Clinical Practice, 1(1), 2-4. [17] Thomson, L.A., et al., 2007, Systematic review of the incidence and characteristics of preventable adverse drug events in ambulatory care. Annals of Pharmacotherapy, 41(9), 1411-1426.

[18] Shanmugam, S., et al., 2011, Impact of pharmaceutical care on quality of life in patients with type 2 diabetes mellitus. Journal of Royal Medical Society, 16(1), 412-418.

[19] Anyama, N., and Adome, R.O., 2003, Community pharmaceutical care: An 8-month critical review of two pharmacies in Kampala. African Health Sciences, 3(2), 87-93.

[20] Dunlop, J.A., and Shas, J.P., 2002, Pharmacist's perspective on pharmaceutical care implementation in New Zealand. Pharmacy World and Science, 24(6), 224-30.

[21] Gloria, N., and Sylvie, P., 2000, Optimizing adherence to pharmaceutical care plan. Journal of American Pharmaceutical Association, 40(4), 475482.

[22]Erah, P.O., and Nwazuoke, J.C., 2002, Identification of standards for pharmaceutical care in Benin City. Tropical Journal of Pharmaceutical Research, 1(2), 55-66.

[23] Oparah, C.A., and Eferakeya, A.E, 2005, Attitude of Nigerian pharmacists towards pharmaceutical care. Pharmacy World and Science, 27(3), 208-214.

[24] Salami, A.A., 2018, Assessment of remote sensing in deriving meteorological data for agricultural purposes in Nigeria. A Ph.D. proposal presented at the department of Geography and Environmental Management, University of Ilorin, Nigeria.

[25] Salami, A.A., Olorunfemi, J.F., and Olanrewaju, R.M., 2020, Geo-spatial analysis of rainfall amounts and rainy days using satellites and ground-based data in Nigeria. Journal of Meteorology and Climate Science, 18 (1). 
[26] National Population Commission, 2016, 2016 Projected population of Federal Republic of Nigeria 2006 Population and Housing Census, Priority Tables, Vol. VII Abuja, Nigeria.

[27]Eze, T.C., Okpala, C.S., and Ogbodo, J.C., 2014, Patterns of inequality in human development across Nigeria's six geopolitical zones. J Dev Ctries Stud., 4(8), 97-101.

[28] World Health Organization, 2015, Nigeria: World Health Organisation statistical profile 2015. Available from: http://www.who.int/gho/countries/nga.pdf?ua=1.

[29]Ekpenyong, A., Udoh, A., Kpokiri, E., and Bates, I., 2018, An analysis of pharmacy workforce capacity in Nigeria. Journal of Pharmaceutical Policy and Practice, 11:20. https://doi.org/10.1186/s40545-018-0147-9.

[30] Ashiru-Oredope, D., Chan, A.H.Y., Olaoye, O., Rutter, V., Babar, Z. and the C.P.A. COVID-19 Action Team, 2020, Needs assessment and impact of COVID-19 on pharmaceutical professionals in 31 commonwealth countries. $\mathrm{J}$ of Pharm Policy and Pract 13, 72, 1-11. https://doi.org/10.1186/s40545020-00275-7.

[31] Smith, A.J., Scahill, L.S., Harrison, J., Carroll, T., and Medlicott, J.N., 2018, Service provision in the wake of a new funding model for community pharmacy. BMC Health Services Research, 18, 2-10. https://doi.org/10.1186/s12913-018-3120-z.

[32] Ayati, N., Saiyarsarai, P., Nikfar, S., 2020-, Short- and long-term impacts of COVID-19 on the pharmaceutical sector. DARU Journal of Pharmaceutical Sciences, 28, 799-805. https://doi.org/10.1007/s40199-020-00358-5.

[33] Miles, S.H., Kaci, H., 2015, Public health and the politics of fear. Am J Bioeth. 15(4), 17-19. https://doi.org/10.1080/15265161.2015.1010994.

[34] Yoon, M.K., Kim, S.Y., Ko, H.S., Lee, M.S., 2016, System effectiveness of detection, brief intervention and refer to treatment for the people with post-traumatic emotional distress by MERS: A case report of community-based proactive intervention in South Korea. Int J Ment Health Syst. 10:51. https://doi.org/10.1186/s13033-016- 0083-5.

[35] Marzo, R.R., Singh, A., Mukti, R.F., 2021, A survey of psychological distress among Bangladeshi people during the COVID-19 pandemic. Clinical Epidemiology and Global Health. 10:1016. https://doi.org/10.1016/j.cegh.2020.100693.

[36]Htay, M.N.N., Marzo, R.R., AlRifai, A. et al., 2020, Immediate impact of COVID-19 on mental health and its associated factors among healthcare workers: a global perspective across 31 countries. J Glob Health. 2020;10, 020382. https://doi.org/10.7189/jogh.10.020381.

[37] Brooks, S.K., Webster, R.K., Smith, L.E., et al., 2020, The psychological impact of quarantine and how to reduce it: rapid review of the evidence. Lancet., 395(10227), 912-920. https://doi.org/10.1016/S0140-6736(20)30460-8.

[38] Nilima, N., Kaushik, S., Tiwary, B., Pandey, P.K., 2021, Psycho-social factors associated with the nationwide lockdown in India during COVID- 19 pandemic. Clin Epidemiol Glob Health, 9, 47-52.

[39]Lai, J., Ma, S., Wang, Y., Cai, Z., Hu, J., Wei, N., et al. 2020, Factors associated with mental health outcomes among health care workers exposed to coronavirus disease 2019. JAMA Netw Open. 3(3), e203976.

[40]Bohlken, J., Schömig, F., Lemke, M.R., Pumberger, M., Riedel-Heller, S.G., 2020, COVID19 Pandemic: Stress Experience of Healthcare Workers - A Short Current Review. Psychiatr Prax., 47(4), 190-7.

[41] Watson, M.C., Silver, K., and Watkins, R., 2019, How does the public conceptualise the quality of care and its measurement in community pharmacies in the UK: A qualitative interview study. BMJ Open, 9e027198, 1-7. Doi: 10.1136/bmjopen2018-027198.

[42] Bukhari, N., Rasheed, H., Nayyer, B., and Babar, Z., 2020, Pharmacists at the frontline beating the COVID-19 pandemic. Journal of Pharmaceutical Policy and Practice, 13, (8), 1-4. https://doi.org/10.1186/s40545-020-00210-w.

[43] Chukwuorji J.C., and Iorfa, S.K., 2020, Commentary on the coronavirus pandemic: Nigeria. Psychological Trauma: Theory, Research, Practice, and Policy, 12(S1), S188- S190. DOI $10.1037 /$ tra0000786.

[44]Dkhar, S.A., Quansar, R., Saleem, S.M. and Khan, S.M., 2020, Knowledge, attitude, and 
practices related to COVID-19 pandemic among social media users in $\mathrm{J} \& \mathrm{~K}$, India. Indian Journal of Public Health, 64(6), 205-210 DOI 10.4103/ijph.IJPH_469_20.

[45]Ilesanmi, O., and Afolabi, A., 2020, Perception and practices during the COVID-19 pandemic in an urban community in Nigeria: A cross-sectional study. PeerJ8:e10038. DOI 10.7717/peerj.10038.

[46]Iorfa, S.K., Ottu, I.F.A., Oguntayo, R., Ayandele, O., Kolawole, S.O., Gandi, G.C., Dangiwa, A.L., and Olapegba, P.O., 2020, COVID19 knowledge, risk perception and precautionary behavior among Nigerians: A moderated mediation approach. medRxiv

DOI 10.1101/2020.05.20.20104786.

[47]Zhong, B-L, Luo, W., Li, H-M., Zhang, Q-Q., Liu, X-G., Li, W-T., and Li, Y., 2020, Knowledge, attitudes and practices towards COVID19 among Chinese residents during the rapid rise period of the COVID-19 outbreak: A quick online cross-sectional survey. International Journal of Biological Sciences, 16(10), 1745-1752 DOI 10.7150/ijbs.45221.

[48] WHO, 2020b, Coronavirus disease (COVID-19) situation report-149 Geneva: World Health Organization. Accessed: 26 August 2020. https:/www.who.int/docs/defaultsource/coronaviruse/situationreports/20200623covid-19-sitrep-155.pdf?sfvrsn=ca01ebe_2.
[49] Al-Hanawi, M.K., Angawi, K., Aishareel, N., Qattan, A.M.N., Helmy, H.Z. ... Aisharqi, O., 2020, Knowledge, attitude and practice toward COVID-19 among the public in the Kingdom of Saudi Arabia: A cross-sectional study. Front. Public Health, 8, 217, 1-10. Doi:10.3389/fpubh.2020.00217.

[50]Witte, K., 1998, Fear as motivator, fear as inhibitor: using the extended parallel process model to explain fear appeal successes and failures. In Andersen, P.A. and Guerrero L.K., (Eds), The Handbook of Communication and Emotion: Research, Theory, Applications, and Contexts (pp. 423-450), San Diego: Academic.

[51] Nabi, R.L., 1999, A cognitive-functional model for the effects of discrete negative emotions on information processing, attitude change, and recall. Communication Theory, 9(3), 292-320. DOI 10.1111/j.1468-2885. 1999. Tb00172. x.

[52]Ufuwa, I.S., Akpa, C.O., Umeokonkwo, C.D., Umoke, M., Oguanuo, C.S., Olorukooba, A.A., Bamgboye, E., and Balogun, M.S., 2020, Knowledge and risk perception towards Lassa fever infection among residents of affected communities in Ebonyi State, Nigeria: Implications for risk communication. BMC Public Health, 20(1), 1-10. DOI 10.1186/s12889-020-8299-3. 